\title{
The Effects of Shot Peening on the Surface Characteristics of 35NCD16 Alloy Steel
}

\author{
Mohamed Benaissa1, Fethi Benkhenafou', Abdelkader Ziadi², Luis Borja Peral Martinez³, \\ Francisco Javier Belzunce ${ }^{3}$, Lyes Douadji ${ }^{*}$
}

\footnotetext{
1 Department of Mechanical Engineering, Faculty of Technology, University Abou Bakr Belkaid, P. O. B. 230, 13000 Tlemcen, Algeria

2 Smart Structures Laboratory/DGRSDT, University Center of Ain-Témouchent, P. O. B. 284, 46000 Ain-Témouchent, Algeria

${ }^{3}$ Department of Materials Science, Campus Gijon, University of Oviedo, East Building, 33203, 33203 Gijón, Spain

${ }^{4}$ Chongqing Institute of Green and Intelligent Technology, Chinese Academy of Sciences, 400714 Chongqing, Fangzheng Avenue 266, China

* Corresponding author, e-mail: Idouadji@cigit.ac.cn
}

Received: 08 October 2018, Accepted: 21 May 2020, Published online: 16 July 2020

\begin{abstract}
Shot-peening is a surface mechanical treatment, widely used to treat metallic parts in the aerospace and automotive industries. This mechanical surface treatment should not be confused with other common applications of other peening treatments, oriented towards cleaning, preparation or surface finishing. Shot peening is a mechanical treatment used to improve the service life of metallic components, especially when they are submitted to cyclic loads. The effect of shot peening on the surface work hardening and residual stress profile of a 35NCD16 steel was studied in this work.
\end{abstract}

Keywords

shot peening, surface treatments, hardening, residual stress, micro hardness, FWHM

\section{Introduction}

The improvement of the local properties of the steel by a surface treatment can be done by thermal, thermochemical or even mechanical means. These treatments increase the surface hardness, by metallurgical transformations or by mechanical hardening. The increase in hardness generally ensures good resistance to wear and also to fatigue due to repeated loading $[1,2]$.

Most of these treatments also introduce compressive stresses in the surface layers of the component due to deformation heterogeneities induced within the workpiece (plastic deformations, volumetric expansions due to changes in temperature or to transformation of certain metallurgical phases).

Shot peening is one of these surface treatments. Referring to the literature dealing with shot peening applied to steels and its effects under different cyclic loadings [3-12], it is nowadays clear that shot peening is a very effective and cost efficient final treatment to increase the fatigue strength of steels. This surface treatment consists in bombarding the surface of the component with a stream of small, high hardness spheres, called shots. These impacts plastically deform the surface layer (increasing local hardness), while the underneath region remains elastic, given rise to a compressive residual stress field [13-20], as it is shown in Fig. 1.

The most important parameters of the residual stress field are the surface compressive residual stress, the maximum compressive residual stress and the total depth of the compressive stress layer and these values depend on the shot peening parameters, shot size and density, Almen

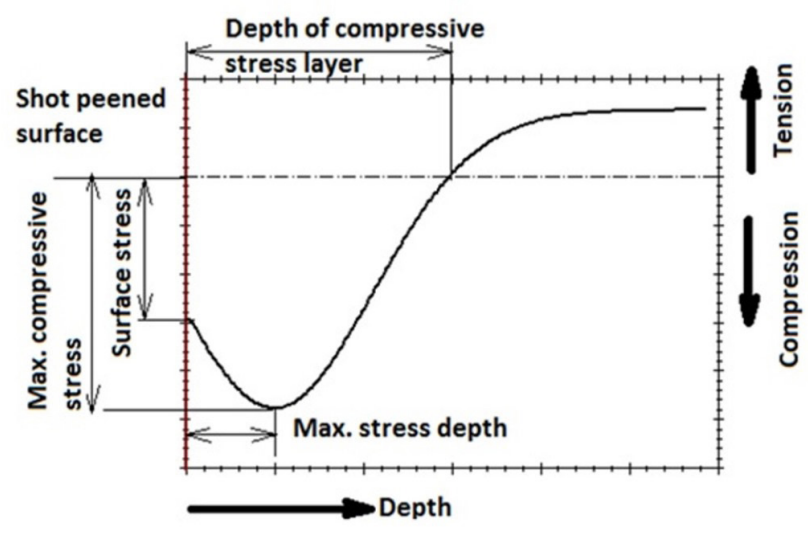

Fig. 1 Effects of shot peening 
intensity, coverage [21, 22]. In order to find the optimum shot peening conditions for particular steel many variables are involved, as steel grade and strength, surface roughness, applied loads [23].

The existence of a residual compressive stress field significantly improves the fatigue behavior of any particular steel component, especially when it is submitted to cyclic bending loads, mainly due to two reasons. First, due to surface work hardening, and secondly, because fatigue cracks only open and grow under tensile loads, so that compressive stresses produces a crack closure effect.

The intensity of a shot peening treatment is measured by the so-called Almen intensity, which is an indirect measurement of the energy of the shot stream when it impacts into the target [24]. Moreover, coverage is defined as the ratio of the area covered by the shot impacts (dimples) to the complete surface of the treated sample, expressed as percentage. The degree of coverage does not increase linearly as a function of the peening time, the approximation to full coverage being exponential, so that full coverage is conventionally assessed when the target has an impacted area of $98 \%$ [25-29].

Under this assumption, a degree of coverage of $200 \%$ corresponds to a peening treatment twice as long as the full coverage treatment $[30,31]$. Incomplete coverage of the surface produces a heterogeneous surface compressive stress field, resulting in earlier nucleation of fatigue cracks, while an overlong peening time gives rise to excessive surface plastic deformation, which can produce surface defects, worsening the fatigue performance of the material [31]. An experimental investigation about this material had been done by Bignonnet and Charkaluk [32]. The results of the study show that this design tool on fatigue developed by the Laboratory of Mechanical Systems Engineering (LASMIS) [33] is able to take into account different loading parameters.

The aim of this paper is to present a systematic study of the effects of conventional shot peening on the surface hardening and residual stress profiles of a 35NCD16 alloy steel.

\section{Fundamental equations for the shot peening}

The residual stresses induced by shot peening are expressed by following the Li et al.'s mechanical approach [34].

The classical Hertz results are used to model the elastic stress field created by the impact. The Hertzian stresses are derived for a position directly below the indenter. The reason for choosing a location exactly below the impacting shot is to simplify the problem. As in [35] state of zero shear stress exists there, thus the stresses are principal and the Hertzian elastic stress tensor can be written as follows:

$T^{e}=\left[\begin{array}{lll}\sigma_{11}^{e} & & \\ & \sigma_{22}^{e} & \\ & & \sigma_{33}^{e}\end{array}\right]$,

where the subscripts 1,2 and 3 represents the axis $x 1, x 2$ and $x 3$, respectively. Fig. 2 gives an idealized illustration of a single shot affecting a surface along with expressions for the indentation radius, $a_{p}$, and maximum elastic pressure, $p$, derived from Hertzian contact theory.

The Hertzian stresses are determined for a position straightforwardly underneath the indenter. The reason for choosing an area exactly below the impacting shot is to simplify the problem.

The corresponding mean stress and strain are:

$\sigma_{m}^{e}=\frac{1}{3}\left(\sigma_{11}^{e}+\sigma_{22}^{e}+\sigma_{33}^{e}\right)$,

$\epsilon_{m}^{e}=\frac{1}{3}\left(\epsilon_{11}^{e}+\epsilon_{22}^{e}+\epsilon_{33}^{e}\right)$.

The elastic deviatoric strain components are found by subtracting the mean strains from the strain tensor. The principal components of this tensor are derived as:

$$
\begin{aligned}
& e_{11}^{e}=\epsilon_{11}^{e}-\epsilon_{m}^{e}=\frac{1}{3}(1+v) \epsilon_{i}^{e}, \\
& e_{22}^{e}=\epsilon_{22}^{e}-\epsilon_{m}^{e}=\frac{1}{3}(1+v) \epsilon_{i}^{e},
\end{aligned}
$$

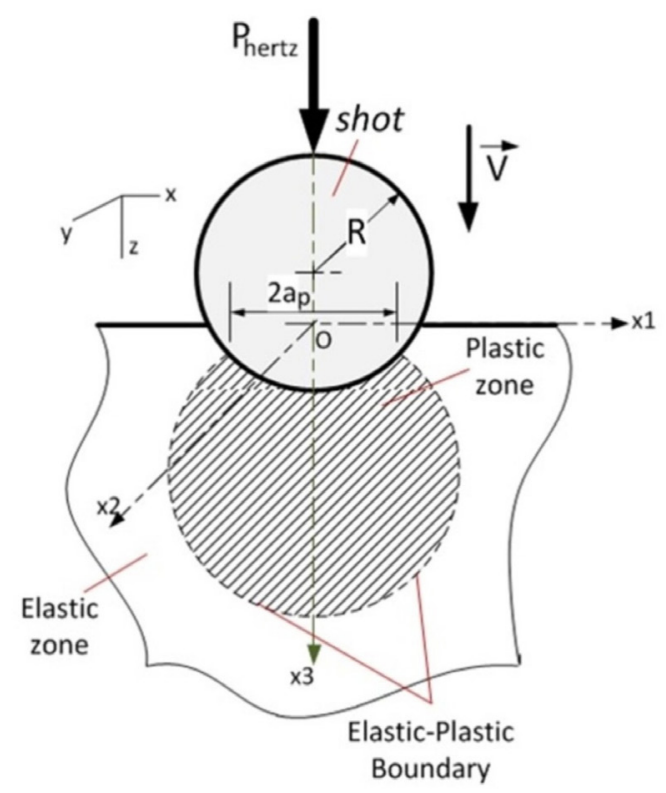

Fig. 2 Schematic of a rigid shot impacting a semi-infinite surface 
$e_{33}^{e}=\epsilon_{33}^{e}-\epsilon_{m}^{e}=-2 e_{11}^{e}=-\frac{2}{3}(1+v) \epsilon_{i}^{e}$.

The principal components of the deviatoric stress tensor in the target material can be expressed as:

$S_{11}^{e}=\sigma_{11}^{e}-\sigma_{m}^{e}=\frac{1}{3} \sigma_{i}^{e}$,

$S_{22}^{e}=\sigma_{22}^{e}-\sigma_{m}^{e}=\frac{1}{3} \sigma_{i}^{e}$,

$S_{33}^{e}=\sigma_{33}^{e}-\sigma_{m}^{e}=-2 S_{11}^{e}=-\frac{2}{3} \sigma_{i}^{e}$.

As in numerous elastic-plastic investigations, the elastic-plastic constitutive relationship associated with the target material can be simplified to a multi-linear one.

A simplified relation [34] will be executed here. By adopting a modifying coefficient, $\alpha$, the elastic-plastic strain $\epsilon_{i}^{p}$ at any depth $x 3$ is calculated from the elastic strain $\epsilon_{i}^{e}$, at the corresponding depth $x 3$ :

$\epsilon_{i}^{p}=\left\{\begin{array}{ll}-\epsilon_{i}^{e} & \text { for } \epsilon_{i}^{e} \leq \epsilon_{s} \\ \epsilon_{s}+\alpha\left(\epsilon_{i}^{e}-\epsilon_{s}\right) & \text { for } \epsilon_{i}^{e}>\epsilon_{s}\end{array}\right.$.

The linearity coefficient $\alpha$ is defined as the ratio of the plastic and elastic indentation radius $[34,36]$,

$\alpha=\frac{a_{p}}{a_{e}}$

and $\epsilon_{S}$ is the strain at yielding.

According to the Hertzian contact theory, when the elastic compression is at its maximum, the radius of the elastic contact circle between the shot and the semi-finite body, is expressed as:

$a_{e}=R\left(\frac{5}{2} \pi \kappa \rho \frac{V^{2}}{E_{0}}\right)^{\frac{1}{5}}$,

where $V$ is the shot velocity, $R$ is the shot radius, $v$ is the target Poisson ratio, $v_{s}$ is the shot Poisson ratio, $\rho$ is the shot density and $\kappa$ is an efficiency coefficient based upon elastic rebound of the shot [37].

The maximum plastic indentation radius of a dent produced by the same shot on an elastic-plastic target under the same velocity [35] is

$a_{p}=R\left(\frac{8 \rho V^{2}}{9 \sigma_{s}}\right)^{\frac{1}{4}}$,

where $\sigma_{s}$ is the yield strength.

According to [34], the equivalent stress, $\sigma_{i}^{p}$, is solved by assuming a multi-linear relationship with the equivalent plastic strain: $\sigma_{i}^{p}= \begin{cases}-\sigma_{i}^{e} & \text { for } \epsilon_{i}^{e}<\epsilon_{s} \\ \epsilon_{s}+\eta\left(\epsilon_{i}^{p}-\epsilon_{s}\right) & \text { for } \epsilon_{s} \leq \epsilon_{i}^{p}<\epsilon_{b} . \\ \sigma_{b} & \text { for } \epsilon_{i}^{p} \geq \epsilon_{b}\end{cases}$

The quantities $\sigma_{s}, \sigma_{b}$, and $\eta$ are the yield stress, ultimate tensile stress and linear strain hardening parameter respectively (Fig. 3).

A great simplification is made by assuming the deviatoric plastic strains take on a similar form as the deviatoric elastic strains. In order to obtain the stress deviators, that are the components of the stress tensor that effectively contribute to the plastic deformation, the strain deviators have to be obtained. Due to the asymmetry of loading the elastic-plastic strain deviators, $e_{i j}^{p}$, are expressed as:

$e_{11}^{p}=\frac{1}{3}(1+v) \epsilon_{i}^{p}$,

$e_{22}^{p}=\frac{1}{3}(1+v) \epsilon_{i}^{p}$

$e_{33}^{p}=-2 e_{11}^{p}=-\frac{2}{3}(1+v) \epsilon_{i}^{p}$.

The next goal is to derive the elastic-plastic deviatoric stresses. Based on the Ilyushin's Elastic-plastic

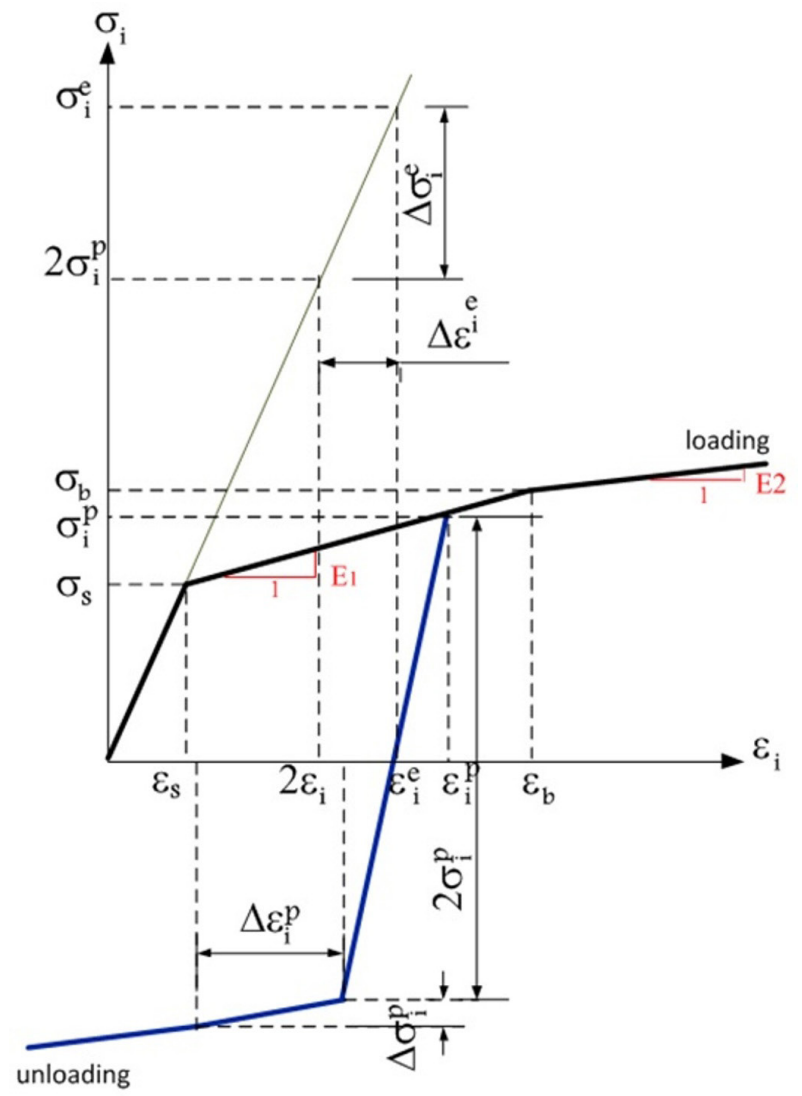

Fig. 3 Schematic diagram for calculating stresses after unloading 
theory [38, 39], the strain deviators $e_{i j}^{p}(j=x 1, x 2, x 3)$ and the elastic-plastic strain $\epsilon_{i}^{p}$ were taken into Eq. (18), then the stress deviators of elastic-plastic model $S_{i j}^{p}$ $(j=x 1, x 2, x 3)$ can be obtained, as shown in Eqs. (19-21):

$S_{i j}^{p} \epsilon_{i}^{p}=\frac{\sigma_{i}^{p}}{1+v} e_{i j}^{p}$

$S_{11}^{p}=\frac{\sigma_{i}^{p}}{(1+v) \epsilon_{i}^{p}} e_{11}^{p}=\frac{\sigma_{i}^{p}}{3}$

$S_{22}^{p}=\frac{\sigma_{i}^{p}}{(1+v) \epsilon_{i}^{p}} e_{22}^{p}=\frac{\sigma_{i}^{p}}{3}$

$S_{33}^{p}=\frac{\sigma_{i}^{p}}{(1+v) \epsilon_{i}^{p}} e_{33}^{p}=-2 \frac{\sigma_{i}^{p}}{3}$.

Finally, the residual stresses resultant from the shot peening process is obtained after the elastic-plastic analysis of the forces that result from the Hertzian elastic contact. Assuming that the amount of deformation is small, unloading is an elastic process until reversed yielding starts and that hydrostatic stress does not introduce plastic deformation, the essential formula for residual stress calculation is $[38,40]$ :

$\sigma_{i j}^{r}=S_{i j}^{p}-S_{i j}^{e}$.

The shot peened material (target material) is assumed to be isotropic. Therefore, the residual stresses can be derived from the following relation [39]:

$\sigma_{i j}^{r}=\left\{\begin{array}{ll}0 & \text { for } \sigma_{i}^{e} \leq \sigma_{s} \\ S_{i j}^{p}-S_{i j}^{e} & \text { for } \sigma_{s} \leq \sigma_{i}^{e}<2 \sigma_{i}^{p}\end{array}\right.$,

which illustrates that there is no residual stress in elastic loading stage. Thus, the residual stresses can be expressed as [20]:

$\sigma_{11}^{r}=\frac{1}{3}\left(\sigma_{i}^{p}-\sigma_{i}^{e}\right)$

$\sigma_{22}^{r}=\frac{1}{3}\left(\sigma_{i}^{p}-\sigma_{i}^{e}\right) \quad$ for $\sigma_{s} \leq \sigma_{i}^{e} \leq 2 \sigma_{i}^{p}$.

$\sigma_{33}^{r}=-2 \sigma_{11}^{r}$

As mentioned by [38], the final residual stresses for $100 \%$ coverage $\left(\sigma_{11}^{R}\right)$ can be obtained by:

$\sigma_{11}^{R}=\sigma_{22}^{R}=\frac{1+v}{1+v} \sigma_{11}^{r}$.

As shown in Fig. 3, the reverse yielding and hardening occurs when $\Delta \sigma_{i}^{e}=\sigma_{i}^{e}-2 \sigma_{i}^{p} \geq 0$. The stress $2 \sigma_{i}^{p}$ is elastically unloaded first.

\section{Material and experimental procedure}

\subsection{Material}

A 35NCD16 steel (36NiCrMo16, Europe EN10083), widely used in the automotive and aeronautical industries for the manufacture of gears, shafts and other structural components was considered in this study. The nominal chemical composition of the steel and its mechanical properties are respectively shown in Tables 1 and 2. Fig. 4 shows the microstructure of the steel, chemically etched with Nital-2\%.

Shot peening was performed by means of a direct compressed air machine (GUYSON Euroblast 4 PF) using conditioned cut wire shots with rounded off edges $(\mathrm{CW}$, $670-730 \mathrm{HV}$, with an average diameter of $0.4 \mathrm{~mm}$ and $0.6 \mathrm{~mm}$ ) and 4 bar [41]. Table 3 shows shot diameter, Almen intensity [27] and surface coverage [42] applied in the different conventional shot peening treatments (CSP1, CSP2 and CSP3).

\begin{tabular}{lccc}
\multicolumn{4}{c}{ Table 1 Nominal chemical composition of 35NCD16 steel (in wt.\%) } \\
\hline $\mathrm{C}$ & $\mathrm{Mn}$ & $\mathrm{Si}$ & $\mathrm{Ni}$ \\
\hline $0.32-0.39$ & $0.5-0.8$ & $0.10-0.40$ & $3.60-4.10$ \\
\hline $\mathrm{Cr}$ & $\mathrm{Mo}$ & $\mathrm{S}$ & \\
$1.60-2.0$ & $0.25-0.45$ & 0.025 & \\
\hline
\end{tabular}

Table 2 Mechanical properties of 35NCD16 steel (elastic modulus, yield strength, ultimate tensile strength, elongation and reduction of area)

\begin{tabular}{lccc}
\hline Material & $V_{\text {test }}(\mathrm{mm} / \mathrm{min})$ & $E(\mathrm{GPa})$ & $\sigma_{v}(\mathrm{MPa})$ \\
\hline $35 \mathrm{NCD} 16$ & 3 & 202 & 486 \\
& $(\mathrm{MPa})$ & $\mathrm{e}[\%]$ & $\mathrm{RA}[\%]$ \\
& 622 & 27.6 & 70 \\
\hline
\end{tabular}

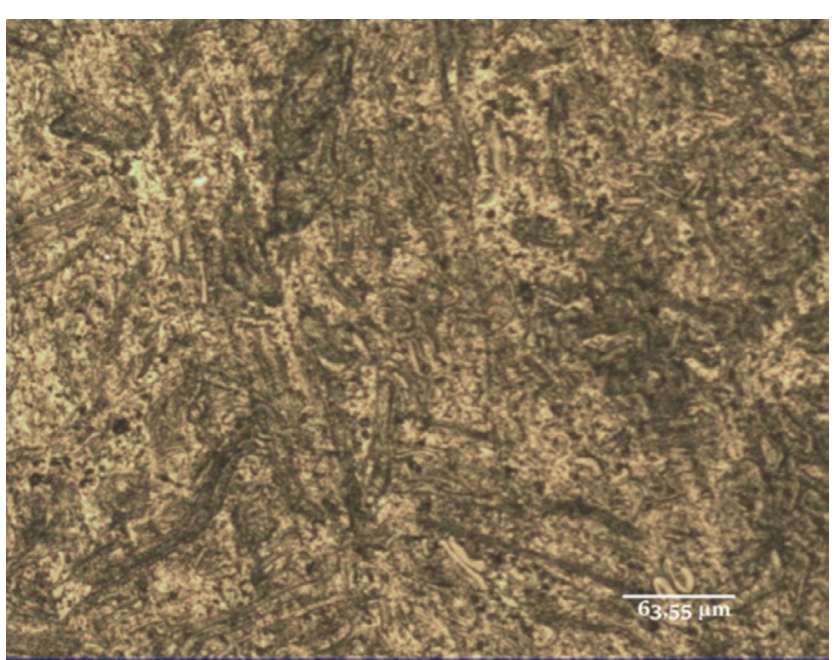

Fig. 4 Microstructure of 35NCD 16 steel 
Table 3 Shot peening treatments

\begin{tabular}{lcccc}
\hline Treatment & $\begin{array}{c}\text { Shot } \\
\text { diameter } \\
(\mathrm{mm})\end{array}$ & $\begin{array}{c}\text { Almen } \\
\text { intensity }\end{array}$ & $\begin{array}{c}\text { Pressure } \\
(\mathrm{MPa})\end{array}$ & $\begin{array}{c}\text { Coverage } \\
(\%)\end{array}$ \\
\hline $\begin{array}{l}\text { Not shot peened } \\
(\mathrm{NSP})\end{array}$ & - & - & - & - \\
$\begin{array}{l}\text { Conventionally shot } \\
\text { peened 1 (CSP1) } \\
\begin{array}{l}\text { Conventionally shot } \\
\text { peened 2 (CSP2) }\end{array}\end{array}$ & $0.4 \mathrm{~mm}$ & $10 \mathrm{~A}$ & 0.4 & 200 \\
$\begin{array}{l}\text { Conventionally shot } \\
\text { peened 3 (CSP3) }\end{array}$ & $0.6 \mathrm{~mm}$ & $10 \mathrm{~A}$ & 0.2 & 200 \\
\hline
\end{tabular}

\subsection{Hardness measurements}

After the shot peening treatments, the samples were transversally cut, embedded in a cold-mounting resin, ground and polished for the measurement of hardness. Vickers microhardness indentations with a load of $200 \mathrm{~g}$ using a dwell time of $15 \mathrm{~s}$ were performed from the treated surface until attaining a depth at which the initial hardness was not modified by the treatment. These tests were performed using a Buehler Micromet 2100 microhardness tester, in accordance to the ASTM E384 standard.

\subsection{Analysis of residual stress profiles}

The X-ray diffraction technique was used to measure the residual stress field produced by the shot peening treatment. These measurements were carried out in depth, step by step, removing a very thin layer of material by means of electro-polishing, in order to obtain the in-depth residual stress profile until compressive stresses disappeared. A solution of acetic acid (94\%) and perchloric acid (6\%) was used for electro-polishing. The results of the in-depth residual stress measurements were corrected using the method described by Moore and Evans [43] in order to account for the removed material. Residual stress measurements were performed in an X-ray diffractometer (Stresstech XSTRESS 3000 G3R), by means of the $\sin 2 \psi$ method [4, 24, 43, 44]. A Cr- $K \alpha$ X-ray source with a wavelength of $0.2291 \mathrm{~nm}(K \alpha=0.2291 \mathrm{~nm})$ was generated under a voltage $30 \mathrm{kV}$ and a current of $6.7 \mathrm{~mA}$. Measurements were taken on the (211) diffraction plane of the ferrite/martensite phase, which was recorded at a $2 \theta$ angle of approximately $156^{\circ}$, and the elastic constant of the selected diffraction plane, $E /(1+v)$, was $168.9 \mathrm{MPa}[5,25,45,46]$. Diffraction data were determined in three different $\phi$ directions on the sample plane: $-45^{\circ}, 0^{\circ}$ and $+45^{\circ}$, subsequently calculating the average result. The longitudinal direction of the samples was designated as $\phi=0$. Nine tilt angles $(\psi)$ between $-45^{\circ}, 0^{\circ}$ and $+45^{\circ}$, a 40 -second exposure time for each single measurement and a $2 \mathrm{~mm}$ diameter collimator were also used. The diffraction peaks were processed via a Pseudo-Voigt adjustment and the background noise was minimized by means of a parabolic expression. The summary of measurement settings is presented in Table 4. In the course of the diffraction measurements, the FWHM parameter, that is the full width of the diffraction peak at its half maximum, was also recorded, this parameter being related with the material hardness.

\section{Results and discussion}

\subsection{Microhardness}

Fig. 5 shows the in-depth microhardness variation from the treated surface to the bulk material of the shot peened specimens (CSP 1, 2 or 3). It is seen that surface hardness significantly increased up to $25 \%$ in comparison with NSP specimen due to work hardening.

Table 4 Experimental parameters employed in the X-ray diffraction analysis.

\begin{tabular}{|c|c|c|c|}
\hline $\begin{array}{l}\text { Wavelength } \\
K \alpha(\mathrm{Cr})\end{array}$ & $0.2291 \mathrm{~nm}$ & Filter & Vanadium \\
\hline $\begin{array}{l}\text { Exposure } \\
\text { time (s) }\end{array}$ & 40 & $\begin{array}{c}\varnothing \text { collimator } \\
(\mathrm{mm})\end{array}$ & 2 \\
\hline Tilt $\psi\left({ }^{\circ}\right)$ & $\begin{array}{c}9 \text { points between } \\
-45 /+45\end{array}$ & $\begin{array}{l}\text { Rotation angle, } \\
\qquad \varphi\left(^{\circ}\right)\end{array}$ & $-45,0$ and 45 \\
\hline Background & Parabolic & Fit & Pseudo-Voigt \\
\hline $\begin{array}{l}\text { Measuring } \\
\text { mode }\end{array}$ & $\chi$-modified & $\begin{array}{l}\text { Diffraction } \\
\text { angle }\end{array}$ & $156^{\circ}$ \\
\hline $\begin{array}{l}\text { Miller } \\
\text { indices (hkl) }\end{array}$ & (211) & $\begin{array}{c}\text { Elastic constant, } \\
E /(1+v)(\mathrm{GPa})\end{array}$ & $168.9 \pm 2.8$ \\
\hline
\end{tabular}

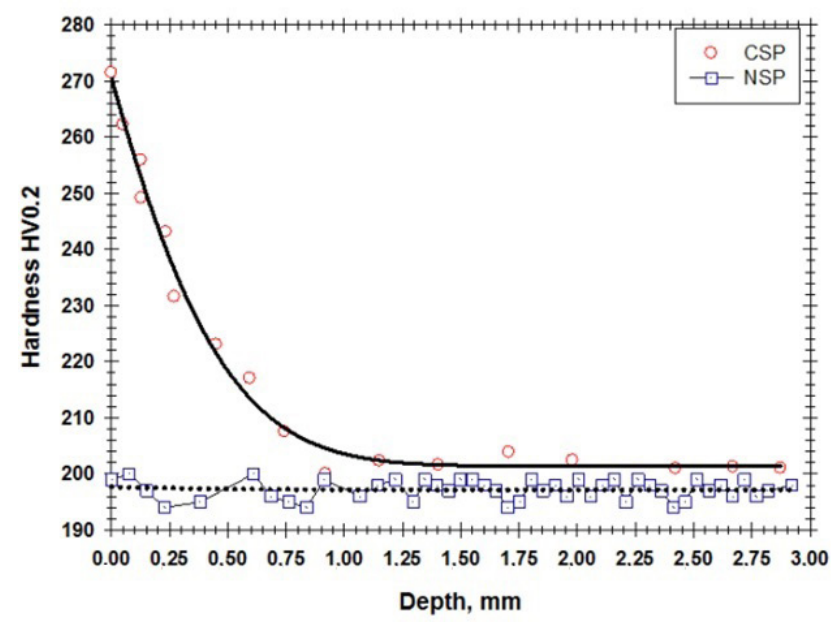

Fig. 5 Hardness profiles 


\subsection{Residual stress profiles}

Conventional shot peened specimens show high surface compressive stresses between 290 and $340 \mathrm{MPa}(0.6-$ $0.7 \mathrm{y})$, maximum compressive stresses of 350-390 $\mathrm{MPa}$ (0.7-0.8 y) and depth submitted to compressive residual stresses varied between 0.25 to $0.27 \mathrm{~mm}$ (Fig. 6). It is also noted the slightly lower residual stress and depth submitted to RS of the treatment applied with the smallest shots (CSP1, CW0.4). The residual stress profile of the nontreated specimens is also recorded in the same figure: any significant residual stress is present, except in a very narrow surface region. The small compressive residual stress measured in this small region is unduly due to machining.

\subsection{Estimation of work-hardened layer thickness}

As it is observed in Fig. 7, the FWHM parameter significantly increases in the near-to-surface region and differences between CSP2 and CSP3 shot peening treatments are barely significant. It is also worth noting that depth

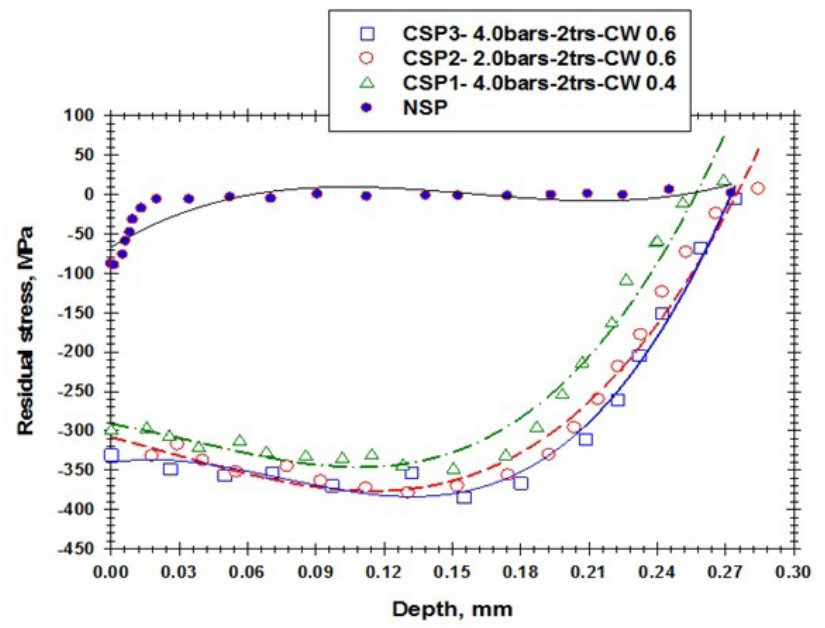

Fig. 6 Residual stress profiles

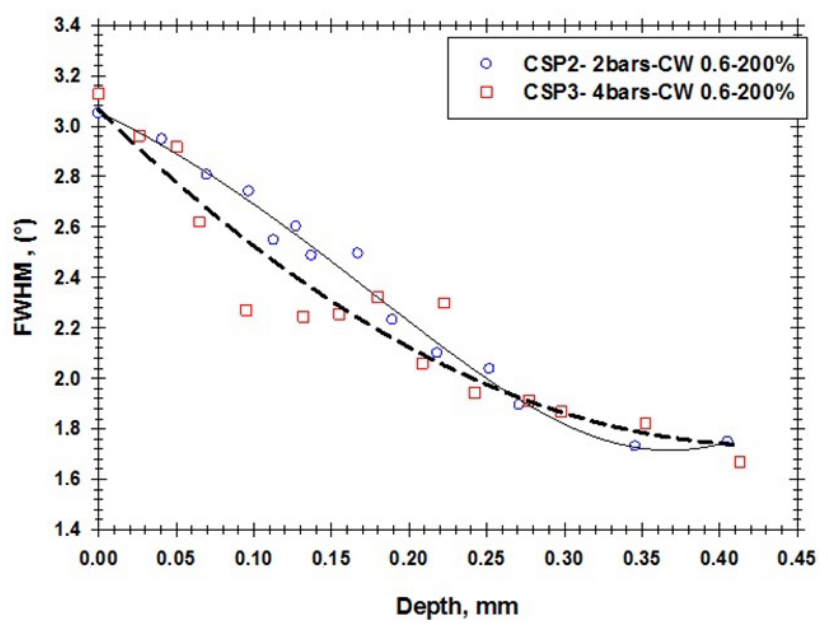

Fig. 7 Full Width at Half Maximum profiles of the region in which the FWHM parameter increased in relation of the value in the non-affected steel (about $0.35 \mathrm{~mm}$ in Fig. 5) is quite similar to the depth submitted to compressive residual stresses (0.25-0.27 in Fig. 4). The depth of the compressed layer approximately corresponds to the depth of the work hardened layer.

Measurements of FWHM parameter were plotted versus the Vickers microhardness using results obtained from CSP2 and CSP3 treatments and a good linear regression was obtained (Fig. 8). It was then demonstrated the use of FWHM as a hardening parameter.

\section{Conclusions}

- Conventional shot peening treatments under a $10 \mathrm{~A}$ intensity give rise to high surface $(0.6-0.7 \mathrm{y})$, and maximum (0.7-0.8 y) compressive stresses, along with a compressive layer depth of $0.25-0.27 \mathrm{~mm}$.

- For the same Almen intensity, slightly lower residual stresses and compressive stress depth were produced in the SP treatment applied using the smallest shots.

- An almost linear correlation was obtained between FWHM parameter and hardness, demonstrating the appropriate use of FWHM as a hardening parameter at least in shot peening applications.

- Shot peening treatments also induce an increase in the hardness of the surface region, due to work hardening, which can be easily and effectively quantified by means of the FWHM parameter.

\section{Acknowledgements}

The authors are grateful for the material support for this study provided by the Materials Science Department of the University of Oviedo.

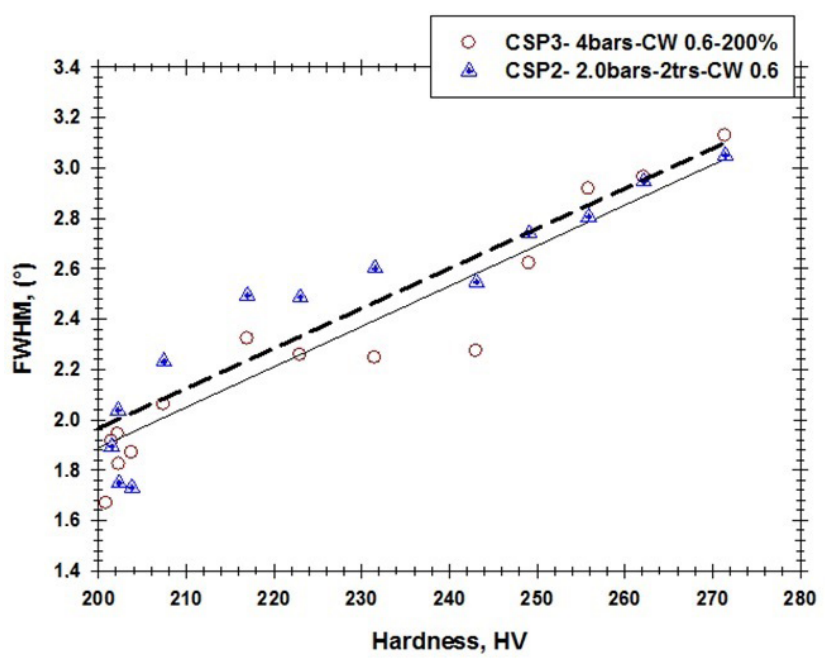

Fig. 8 FWHM parameter versus Vickers microhardness 


\section{References}

[1] Boniardi, M., D'Errico, F., Tagliabue, C. "Influence of carburizing and nitriding on failure of gears - A case study", Engineering Failure Analysis, 13(3), pp. 312-339, 2006. https://doi.org/10.1016/j.engfailanal.2005.02.021

[2] Benkhenafou, F., Fernández Pariente, I., Javier Belzunce, F., Ziadi, A., Shi, M. Q., Douadji, L. "Mechanical Analysis of Low and High Chromium Steels Used in Hot Strip Work Rolls", Solid State Phenomena, 279, pp. 3-9, 2018.

https://oi.org/10.4028/www.scientific.net/SSP.279.3

[3] Hassani-Gangaraj, S. M., Moridi, A., Guagliano, M. "From conventional to severe shot peening to generate nanostructured surface layer: A numerical study", IOP Conference Series: Materials Science and Engineering, 63, Article Number: 012038, 2014. https://doi.org/10.1088/1757-899X/63/1/012038

[4] ASM International Handbook Committee "ASM Handbook. Vol. 5, Surface Engineering", ASM International: The Materials Information Society, Materials Park, OH, USA, 1994.

[5] Llaneza, V., Belzunce, F. J. "Study of the effects produced by shot peening on the surface of quenched and tempered steels: roughness, residual stresses and work hardening", Applied Surface Science, 356, pp. 475-485, 2015.

https://doi.org/10.1016/j.apsusc.2015.08.110

[6] Lundberg, M. "Residual Stresses and Fatigue of Shot Peened Cast Iron", PhD thesis, Linköping University, 2013.

[7] Schulze, V. "Modern Mechanical Surface Treatment", WILEYVCH Verlag GmbH \& Co. KGaA, Weinheim, Germany, 2005.

[8] Smaglenko, F. P., Gryaznov, B. A., Gorodetskii, S. S. "Influence of machining methods on the residual-stress distribution and fatigue strength of steel ShKh15 specimens", Strength of Materials, 9(2), pp. 145-150, 1977.

https://doi.org/10.1007/BF01528372

[9] Troshchenko, B. T., Prokopenko, A. V., Lyalikov, S. M. "Effect of residual stresses on the fatigue resistance of structural steels and alloys containing surface defects", Strength of Materials, 21(8), pp. 975-981, 1989.

https://doi.org/10.1007/BF01529367

[10] Fernández Pariente, I., Guagliano, M. "Influence of Shot Peening Process on Contact Fatigue Behavior of Gears", Materials and Manufacturing Processes, 24(12), pp. 1436-1441, 2009. https://doi.org/10.1080/10426910903386097

[11] Dalaei, K., Karlsson, B., Svensson, L. E. "Stability of residual stresses created by shot peening of pearlitic steel and their influence on fatigue behaviour", Procedia Engineering, 2(1), pp. 613-622, 2010.

https://doi.org/10.1016/j.proeng.2010.03.066

[12] Scheaua, F. "Modelling of the visco-elastic pendular hybrid system with dissipative rolling elements", In: IOP Conference Series: Materials Science and Engineering, 591, Article Number: 012029, 2019.

https://doi.org/10.1088/1757-899X/591/1/012029

[13] Torres, M. A. S., Voorwald, H. J. C. "An evaluation of shot peening, residual stress and stress relaxation on the fatigue life of AISI 4340 steel", International Journal of Fatigue, 24(8), pp. 877-886, 2002. https://doi.org/10.1016/S0142-1123(01)00205-5
[14] Dalaei, K., Karlsson, B. "Influence of overloading on fatigue durability and stability of residual stresses in shot peened normalized steel", Materials Science and Engineering: A, 528(24), pp. 7323-7330, 2011. https://doi.org/10.1016/j.msea.2011.06.002

[15] Kawagoishi, N., Nagano, T., Moriyama, M., Kondo, E. "Improvement of Fatigue Strength of Maraging Steel by Shot Peening", Materials and Manufacturing Processes, 24(12), pp. 1431-1435, 2009. https://doi.org/10.1080/10426910903386055

[16] Rudnitskii, N. M. "Evaluation of the effect of residual stresses and surface layer hardening on the fatigue strength of components", Strength of Materials, 13(10), pp. 1220-1226, 1981. https://doi.org/10.1007/BF00775881

[17] Widmark, M., Melander, A. "Effect of material, heat treatment, grinding and shot peening on contact fatigue life of carburised steels", International Journal of Fatigue, 21(4), pp. 309-327, 1999. https://doi.org/10.1016/S0142-1123(98)00077-2

[18] Korznikov, A. V., Ivanisenko, Y. V., Laptionok, D. V., Safarov, I. M., Pilyugin, V. P., Valiev, R. Z. "Influence of severe plastic deformation on structure and phase composition of carbon steel", Nanostructured Materials, 4(2), pp. 159-167, 1994. https://doi.org/10.1016/0965-9773(94)90075-2

[19] Harada, Y., Fukauara, K., Kohamada, S. "Effects of microshot peening on surface characteristics of high-speed tool steel", Journal of Materials Processing Technology, 201(1-3), pp. 319-324, 2008. https://doi.org/10.1016/j.jmatprotec.2007.11.247

[20] Wang, S., Li, Y., Yao, M., Wang, R. "Compressive residual stress introduced by shot peening", Journal of Materials Processing Technology, 73(1-3), pp. 64-73, 1998. https://doi.org/10.1016/S0924-0136(97)00213-6

[21] Zhang, J. W., Lu, L. T., Shiozawa, K., Shen, X. L, Yi, H. F., Zhang, W. H. "Analysis on fatigue property of microshot peened railway axle steel", Materials Science and Engineering: A, 528(3), pp. 1615-1622, 2011. https://doi.org/10.1016/j.msea.2010.10.086

[22] Eleiche, A. M., Megahed, M. M., Abd-Allah, N. M. "The shot-peening effect on the HCF behavior of high-strength martensitic steels", Journal of Materials Processing Technology, 113(1-3), pp. 502-508, 2001.

https://doi.org/10.1016/S0924-0136(01)00601-X

[23] Bhuvaraghan, B., Srinivasan, S., Maffeo, B. "Optimization of the fatigue strength of materials due to shot peening: A Survey", International Journal of Structural Changes in Solids, 2, pp. 33-63, 2010.

[24] Chaib, M., Megueni, A., Ziadi, A., Guagliano, M., Varela Belzunce, F. J. "Experimental study of the shot peening treatment effect on austenitic stainless steel", International Journal of Materials and Product Technology (IJMPT), 53(3-4), pp. 298-314, 2016. https://doi.org/10.1504/IJMPT.2016.079197

[25] Vielma, A. T., Llaneza, V., Belzunce, F. J. "Effect of coverage and double peening treatments on the fatigue life of a quenched and tempered structural steel", Surface and Coatings Technology, 249, pp. $75-83,2014$. https://doi.org/10.1016/j.surfcoat.2014.03.051 
[26] Renaud, P. "Modélisation numérique du grenaillage des pièces initialement cémentées ou carbonitrurées" (Shot-blasting modeling of carburized or carbonized workpieces), $\mathrm{PhD}$ thesis, Arts et Métiers Paris Tech (Arts et Métiers de Paris), 2011. (in French)

[27] Almen, J. O., Black, P. H. "Residual Stresses and Fatigue in Metals", McGraw-Hill, New York, NY, USA, 1963.

[28] Leghorn, G. "The Story of Shot Peening", Journal of the American Society for Naval Engineers, 69(4), pp. 653-666, 1957. https://doi.org/10.1111/j.1559-3584.1957.tb03244.x

[29] Maleki, E., Unal, O., Kashyzadeh K. R. "Effects of conventional, severe, over, and re-shot peening processes on the fatigue behavior of mild carbon steel", Surface and Coatings Technology, 344, pp. $62-74,2018$.

https://doi.org/10.1016/j.surfcoat.2018.02.081

[30] Kirk, D. "Theoretical Principles of Shot Peening Coverage", The Shot Peener, 19(2), pp. 24-28, 2005.

[31] Ciuffini, A. F., Barella, S., Peral Martínez, L. B., Mapelli, C., Fernández Pariente, I. "Influence of Microstructure and Shot Peening Treatment on Corrosion Resistance of AISI F55-UNS S32760 Super Duplex Stainless Steel", Materials, 11(6), Article Number: 1038, 2018. https://doi.org/10.3390/ma11061038

[32] Bignonnet, A., Charkaluk, E. "Thermomechanical fatigue in the automotive industry", European Structural Integrity Society, 29, pp. 319-330, 2002. https://doi.org/10.1016/S1566-1369(02)80088-7

[33] Yazdi, S., Retraint, D., Lu, J. "Experimental Study of Residual Stress Distributions in Quenched Parts by the Incremental Large Hole Drilling Method and by the Neutron Diffraction Method", Journal of Testing and Evaluation, 28(4), pp. 282-289, 2000. https://doi.org/10.1520/JTE12106J

[34] Li, J. K., Mei, Y., Duo, W., Renzhi, W. "Mechanical approach to the residual stress field induced by shot peening", Materials Science and Engineering: A, 147(2), pp. 167-173, 1991. https://oi.org/10.1016/0921-5093(91)90843-C

[35] Shen, S., Atluri, S. N. "An Analytical Model for Shot-Peening Induced Residual Stresses", Computers, Materials and Continua, 4(2), pp. 75-85, 2006.

[36] Miao, H. Y., Larose, S., Perron, C., Lévesque, M. "An analytical approach to relate shot peening parameters to Almen intensity", Surface and Coatings Technology, 205(7), pp. 2055-2066, 2010. https://doi.org/10.1016/j.surfcoat.2010.08.105
[37] Johnson, K. L. "Contact mechanics", Cambridge University Press, Cambridge, UK, 1985.

[38] Franchim, A. S., de Campos, V. S., Travessa, D. N., de Moura Neto, C. "Analytical modelling for residual stresses by shot peening", Materials \& Design, 30(5), pp. 1556-1560, 2009. https://doi.org/10.1016/j.matdes.2008.07.040

[39] Iliushin, A. A. "Plasticity", National Press of Technical and Theoretical Literature, Moscow, Russia, 1948.

[40] Yah, H. "Local Stress and Its Application", Mechanical Engineering Press, Beijing, China, 1986.

[41] Llaneza, V., Belzunce F. J. "Study of the effects produced by shot peening on the surface of quenched and tempered steels: roughness, residual stresses and work hardening", Applied Surface Science, 356, pp. 475-485, 2015.

https://doi.org/10.1016/j.apsusc.2015.08.110

[42] Bagherifard, S., Ghelichi, R., Guagliano, M. "On the shot peening surface coverage and its assessment by means of finite element simulation: A critical review and some original developments", Applied Surface Science, 259, pp. 186-194, 2012. https://doi.org/10.1016/j.apsusc.2012.07.017

[43] Moore, M. G., Evans, W. P. "Mathematical Correction for Stress Layers in X-Ray Diffraction Residual Stress Analysis", SAE Transactions, 66, pp. 340-345, 1958. https://doi.org/10.4271/580035

[44] Noyan, I. C., Cohen, J. B. "Residual Stress: Measurement by Diffraction and Interpretation", Springer Science + Business Media, New York, NY, USA, 1987. https://doi.org/10.1007/978-1-4613-9570-6

[45] Prevey, P. S. "X-Ray Diffraction Stress Techniques", In: Whan, R. E. (ed.) Materials Characterization, ASM International, Novelty, $\mathrm{OH}$, USA, 1996.

[46] Fitzpatrick, M. E., Fry, A. T., Holdway, P., Kandil, F. A., Shackleton, J., Suominen, L. "NLP Measurement Good Practice Guide No. 52.: Determination of residual stresses by X-ray diffraction", Teddington, UK, 2002 